\title{
Do Endocrinopathies Cause Changes in Transverse Carpal Ligament Thickness and Carpal Tunnel Area in Carpal Tunnel Syndrome?
}

\author{
(1) Numan Karaarslan¹, (D) Abdullah Talha Şimşek1 ${ }^{1}$, (1) Kadir Öznam², (1) Ahmet Murat Bülbül2 \\ 1 Tekirdağ Namık Kemal University School of Medicine, Department of Neurosurgery, Tekirdağ, Turkey \\ 2Istanbul Medipol University School of Medicine, Department of Orthopaedic and Traumatology, Istanbul, Turkey
}

\section{Abstract}

Objective: The purpose of this study was to investigate the effect of transverse carpal ligament (TCL) thickness and the size of carpal tunnel area on clinical findings and electrophysiological changes through the wrist magnetic resonance imaging (MRI).

Methods: In this prospective study, the thickness of the TCL and the carpal tunnel areas of preoperative cases diagnosed with carpal tunnel syndrome (CTS) were measured via wrist MRI results. The effect of TCL thickness and carpal tunnel area on endocrinopathies such as diabetes mellitus (DM) and hypothyroidism and the effect of these variables on clinical findings and electrophysiologic changes were evaluated in the light of the literature.

Results: TCL thickness and carpal tunnel area were not statistically significant among DM, hypothyroidism and electrophysiological changes $(\mathrm{p}>0.05)$.

Conclusion: This study include one of the limited researches comparing the carpal tunnel area and TKL thickness in cases with and without endocrinopathy CTS. However, there is a need for further researches that have a greater number of cases, including multi-centered, differentwinged people.

Keywords: Carpal tunnel syndrome, diabetes mellitus, hypothyroidism, transverse carpal ligament

\section{INTRODUCTION}

Thanks to the developing technology, many branches, especially orthopedic surgeons and neurosurgeons, frequently benefit from magnetic resonance imaging (MRI) while making a clinical diagnosis (1-6). In carpal tunnel syndrome (CTS), an ankle MRI examination is auxiliary imaging used, especially in cases such as evaluation of preoperative intra-canal space-occupying lesions (SOL) and detection of postoperative complications $(2,7)$.

From past to present, after the open CTS the weakness of the transverse carpal ligament (TCL) on the postoperative digital flexor muscles is evaluated, and the effect of the incision of the ligament on the volar migration of the median nerve and digital flexor tendons is investigated (1) or in idiopathic CTS association of morphological anomalies with the severity of this syndrome are assessed with the help of MRI (6). However, in these trials, generally live mammalians like horses and donkeys are used instead of volunteers $(4,5)$. It is known that the sensitivity of animal tissues and human tissues is different $(7,8)$. In line with this proven scientific fact, the results obtained from animal experiments using live mammals are different and do not always reflect the truth (7-11). Evaluation of the literature reveals that in studies where live mammal subjects are not used,

Phone: +90 5057677266 E-mail: numikara@yahoo.com ORCID ID: orcid.org/0000-0001-5590-0637

Cite this article as: Karaarslan N, Şimșek AT, Öznam K, Bülbül AM. Do Endocrinopathies Cause Changes in Transverse Carpal Ligament Thickness and Carpal Tunnel Area in Carpal Tunnel Syndrome? Eur Arch Med Res 2020; 36 (1):45-51

${ }^{\circ}$ Copyright 2020 by the University of Health Sciences Turkey, Okmeydanı Training and Research Hospital

European Archives of Medical Research published by Galenos Publishing House. 
commercial cell lines are generally preferred $(12,13)$. However, their results are not trusted because commercial cell lines include uniform cells, they don't contain the microenvironment like the extracellular matrix around them, and their phenotypic and genotypic properties change in time (14-19).

In this article, animal tissue or commercial cell lines were not used while creating the experimental setup. We believe that the results may be strong, as the data from this study are from the human wrist MRI and electromyography (EMG) tests. The aim of this scientific research was to investigate the relationship between TCL thickness and carpal tunnel area size with endocrinopathies and electrophysiological changes in patients diagnosed with CTS and included in this research.

\section{METHODS}

This prospective research was performed after approval from the Ethics Committee of Namık Kemal University Medical School with a number of 2017/55/05/04 and consent from the volunteers. In order to minimize analysis-related errors, similar measurements were performed by similar researchers.

\section{Tools}

The EMG device which was used to record the electrical activity of muscle and peripheral nerves and measure their functions was Nihon Kodhen Corporation Tokyo, Japan (\#80270), and the MRI device was 1.5 Tesla, GE HEALTHCARE-OPTIMA MRA360.

\section{Working principle}

In this prospective research, we measured TCL thickness and carpal tunnel size in wrist MRI's of preoperative CTS patients $(n=40)$. Then, we evaluated whether TCL thickness and carpal tunnel size change with endocrinopathies like diabetes mellitus (DM) and hypothyroidism and the effects of these variables on clinical findings and electrophysiologic changes. The association of carpal tunnel size and TCL thickness with endocrinopathies, and whether these measurements have effects on EMG findings were statistically assessed and discussed considering the literature.

\section{Inclusion and Exclusion Criteria for the Cases}

The study universe consisted of 67 patients who had complaints due to the involvement of sensory fibers of the median nerve $(n=67)$.

Biochemical and hormonal assessments were performed for those cases who had flammable pain with tingling and numbness at the distal part of the wrist, whose first three fingers and the lateral half of the fourth finger were affected, whose sleep is interrupted due to numbness and paresthesia and shake their hands to relieve the pain, whose pain radiates to forearm and shoulder but spares neck, who feels hands painful and swollen especially in the morning, who have muscle weakness and atrophy at thenar region, and especially who have clumsiness which increases with activity and weakness in grasping objects. Although the CTS occurs due to idiopathic causes, several blood tests were performed for differential diagnosis. These tests included fasting plasma glucose, erythrocyte sedimentation rate, rheumatoid factor, anti-nuclear antibody, thyroid function tests, uric acid, and predisposing metabolic storage diseases.

After biochemical laboratory tests, the subjects were taken to the EMG laboratory to be evaluated with EMG. Mild CTS patients who have slowed median distal sensory conduction and lower than normal sensory action potential amplitude by orthodromic, antidromic, or palmar pathway $(\mathrm{n}=10)$, moderate CTS patients who had increased median nerve distal motor latency in addition to mild CTS symptoms ( $\mathrm{n}=4$ ), and subjects who had Raynaud phenomenon $(n=1)$, dry skin $(n=2)$, swelling $(n=2)$, and color changes $(n=3)$ at median nerve distribution area were excluded. In the study group, there was no case with tumoral lesions, bone fractures, neural cyst, or ganglion cyst. If there were any, those cases also would have been excluded.

Subjects who have severe CTS $(n=40)$ according to $E M G$ findings such as frequently absent sensory action potential, "-" thenar response, a severe decrease in amplitude, delayed distal latencies, and partial denervation in thenar EMG were included in this study.

\section{Electrodiagnosis and EMG}

An EMG analysis was performed for all patients who were clinically thought to have CTS and included in the study to differentiate CTS from cervical spondylosis, brachial plexus lesions, peripheric polyneuropathies, thoracic outlet syndrome, multiple sclerosis, cervical (C5-6) radiculopathies, entrapment neuropathies at other sites of the median nerve, and to measure the severity of median nerve injury. During the performance of these measurements, the guidelines of the American Association of Electrodiagnostic Medicine, American Academy of Neurology, and the American Academy of Physical Medicine and Rehabilitation were taken into account. The diagnosis was made by measuring distal/proximal sensory ratio, which is the ratio of digit-wrist conduction velocity and palm-wrist conduction velocity performed from the third digit. According to this sensory conduction was measured at a $13-14 \mathrm{~cm}$ area in which CTS symptoms are seen. These values were compared with the conduction velocities of other regions that innervate 
neighboring areas. According to the EMG results, the cases were grouped into 4 categories as normal, mild, moderate, and severe CTS (20).

In radiological evaluation, multiplanar MRI was used because it demonstrates musculoskeletal system diseases and soft tissue problems with high resolution and multiplanar cross-sectional evaluation (Figure 1a). The MRI sequences to be measured were fat-suppressed proton density axial (PDA) evaluation, and axial T1 weighted evaluation. PDA evaluation parameters were TR: 2500, TE: 13, FOV: $8 \mathrm{~cm}$, matrix: 512x256, slice thickness: $2 \mathrm{~mm}$, gap: $0.5 \mathrm{~mm}$, NEX: 2, ETL: 8, BW: 14 and axial T1A evaluation parameters were TR: 500, TE: 10, FOV: 8 matrix: 512x256, slice thickness: $2 \mathrm{~mm}$, gap: $0.5 \mathrm{~mm}$, NEX: 2, BW: 14. During MRI evaluation antero-posterior thickness of flexor retinaculum was performed at the level of hamulus of hamatum (Figure 1b). In addition, an increase in median nerve thickness was measured at the psiform bone level, and median nerve compression and carpal tunnel area were measured the hamatum level (Figure 1c) (21).

The measurements were performed with Sectra pacs (version 18.2 ; 2017) program.

\section{Surgical Technique}

During the preoperative evaluation, all of the cases were taken to the operation table. While the patients were at a neutral supine position, the antisepsis of the surgical area was achieved by $10 \%$ polyvinylpyrolidone solution. The hand was positioned as palm facing upwards. A longitudinal, approximately 1-1.5 $\mathrm{cm}$ incision line was marked, starting from the Kaplan cardinal line close to the flexor retinaculum, along the imaginary line passing through the radial edge of the fourth finger. To achieve anesthesia at incision line, lidocaine and epinephrine solutions were applied in $4 \mathrm{~mL}$ volume after dilution within $0.9 \%$ isotonic sodium chloride solution. Skin and subcutaneous tissue were passed with a surgical incision. TCL was identified and incised. The median nerve was decompressed. Bleeding control was established, subcutaneous tissue and the skin were sutured in accordance with the anatomical origin, and the operation was terminated.

\section{Statistical Analysis}

The data were analyzed with SPSS 20.0 package program. Descriptive statistics were given as mean \pm standard deviation or median and frequency. Fisher's exact test and the FisherFreeman Halton tests were used to compare qualitative data. Because data obtained after the exclusion of subjects who didn't meet research criteria were not normally distributed, MannWhitney U test was used instead of the student's t-test. Then, the association was controlled using Spearman's Rho test. The results were evaluated with a 95\% confidence interval, and $p<0.05$ was accepted as the significance level.

\section{RESULTS}

Demographic features and accompanying metabolic and other diseases were classified in subjects' diagnoses as CTS (Table 1).

No significant association was detected between CTS area and TCL thickness ( $r s=-0.020 ; p=0,903 ; p>0.05$ ) (Table 2). Also, there was no significant association between TCL thickness and carpal tunnel area with DM, hypothyroidism, and electrophysiological variables $(p>0.05)$ (Table 3$)$.

\section{DISCUSSION}

In order to diagnose CTS, anamnesis, physical, and neurological examinations of the subject are evaluated together (22), and diagnostic provocative and electrodiagnostic tests are performed
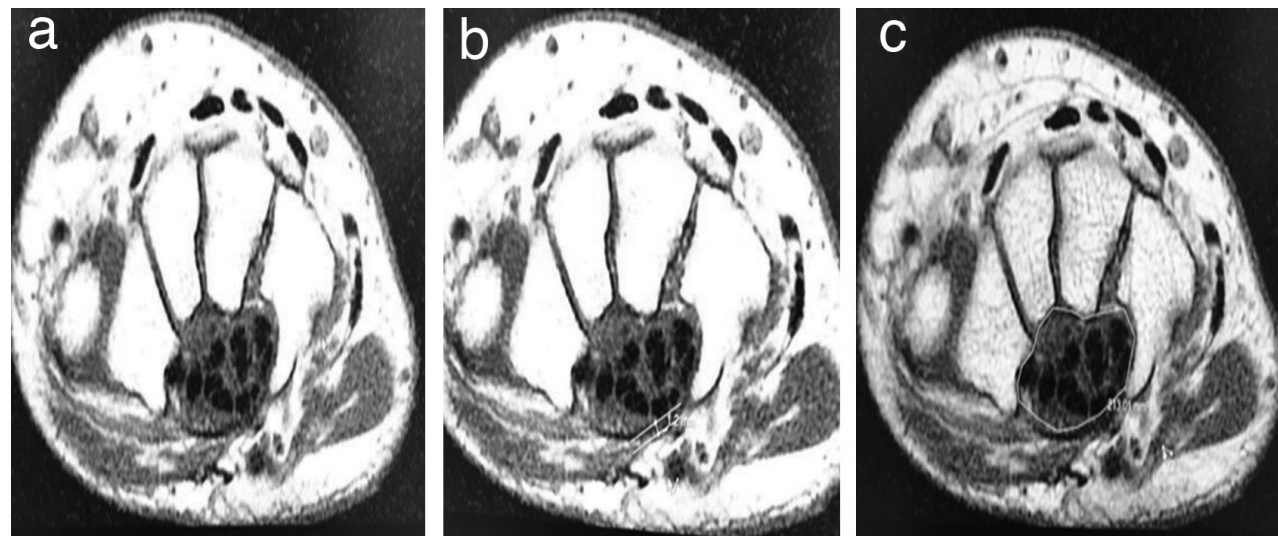

Figure 1. Noncontrast T1 Hand MRI. Axial sections through the wrist. a) Vertical section of the carpal tunnel, b) TCL thickness, c) measurement of carpal tunnel area

TCL: Transverse carpal ligament 
for subjects who are believed to have CTS (23). By this way, CTS may be differentiated from other neuropathies (24).

After excluding rheumatological diseases and conditions such as sequelae of old fractures, radiological methods are used to evaluate parameters such as space occupying lesions in carpal tunnel, decreased carpal tunnel area due to osseous pathologies, and TCL thickness. (3,23). After Fornage et al. (25) detected TCL thickening in CTS patients using ultrasonography, hand MRI was

\begin{tabular}{|c|c|c|}
\hline Age (Years) & Mean \pm standard deviation & $55.60 \pm 11.38$ \\
\hline \multirow{2}{*}{$\begin{array}{l}\text { Sex } \\
\text { (Frequency) }\end{array}$} & Female & $38(95 \%)$ \\
\hline & Male & $2(5 \%)$ \\
\hline \multirow{3}{*}{$\begin{array}{l}\text { Height }(\mathrm{cm}) \\
\text { Weight }(\mathrm{kg}) \\
\text { Body mass } \\
\text { Index }\left(\mathrm{kg} / \mathrm{cm}^{2}\right)\end{array}$} & Mean \pm standard deviation & $160.33 \pm 7.5$ \\
\hline & Mean \pm standard deviation & $77.5 \pm 14.40$ \\
\hline & Mean \pm standard deviation & $30.24 \pm 5.79$ \\
\hline \multirow{3}{*}{$\begin{array}{l}\text { Accompanying } \\
\text { diseases } \\
\text { (frequency) }\end{array}$} & No & $24(60.0 \%)$ \\
\hline & Yes & $16(40.0 \%)$ \\
\hline & Diabetes mellitus & $8(20.0 \%)$ \\
\hline \multirow{3}{*}{$\begin{array}{l}\text { Type of } \\
\text { accompanying } \\
\text { disease } \\
\text { (Frequency) }\end{array}$} & Hypertension & $9(22.5 \%)$ \\
\hline & Rheumatoid arthritis & $7(17.5 \%)$ \\
\hline & Hypothyroidism & $2(5.9 \%)$ \\
\hline
\end{tabular}

started to be used in 1986, and it gained popularity in years. Neurophysiologic studies (NPS) have an important role in CTS diagnosis today, but there are studies in the literature that reported NPS does not help to diagnose typical CTS patients, and it results in more confusion than its benefits (26). Later, studies emerged that emphasized that neurophysiological studies have important roles in CTS diagnosis $(27,28)$. Hand ultrasonography and conventional hand MRI studies during the same years demonstrated the fibrosis and edema in TCL in CTS patients (29).

With the advance in diagnostic evaluation tools, studies emerged in the literature, which demonstrated that in endocrinopathies like DM and hypothyroidism, TCL hypertrophy causes CTS. Based on this, surgical decompression for CTS cases due to DM may relieve sensory findings (30).

In this study, contrary to the literature, no statistically significant association could be found between TCL thickness and carpal tunnel area with DM, hypothyroidism, and electrophysiologic variables.

Netscher et al. (1) investigated the role of TCL in postoperative weakness and flexor digital canal system in CTS patients who were operated with open surgery. They used cadavers to study the effect of TCL on flexor tendons during the course of flexor tendons in the carpal tunnel. Using MRI imaging, they demonstrated that compared with the patients who were operated with other methods, patients who had TCL reconstruction with flap

Table 2. Comparison of carpal tunnel area and transverse ligament thickness in cases that have or don't have accompanying endocrinopathy

\begin{tabular}{|l|l|l|l|l|}
\hline \multicolumn{2}{|l|}{} & Carpal tunnel area $\left(\mathbf{m m}^{2}\right)$ & Transverse ligament thickness $(\mathrm{mm})$ \\
\hline \multirow{3}{*}{ DM } & Yes $(\mathrm{n}=8)$ & Mean \pm SD & $206.94 \pm 27.22$ & $0.94 \pm 0.16$ \\
\cline { 2 - 5 } & No $(\mathrm{n}=30)$ & Mean \pm SD & $202.71 \pm 28.79$ & $0.96 \pm 0.14$ \\
\hline \multirow{3}{*}{ Hypothyroidism } & $\mathrm{p}^{*}$ & 0.624 & 0.945 \\
\hline & Yes $(\mathrm{n}=2)$ & Mean \pm SD & $187.47 \pm 14.80$ & $1.00 \pm 0.17$ \\
\cline { 2 - 5 } & No $(\mathrm{n}=30)$ & Mean \pm SD & $202.71 \pm 28.79$ & $0.96 \pm 0.14$ \\
\hline *Alpha significance values obtained after Mann-Whitney, DM: Diabetes mellitus, SD: Standard deviation & 0.282 \\
\hline
\end{tabular}

Table 3. The association of TCL thickness, and carpal tunnel area with diabetes mellitus, hypothyroidism, and electrophysiological variables

\begin{tabular}{|c|c|c|c|c|c|}
\hline & & & DM & Hypothyroidism & EDS \\
\hline \multirow{6}{*}{ Spearman's rho } & \multirow[t]{2}{*}{ DM } & Correlation Coefficient & 1.000 & -0.115 & -0.120 \\
\hline & & Sig. $(2 \text {-tailed })^{*}$ & - & 0.481 & 0.459 \\
\hline & \multirow[b]{2}{*}{ Hypothyroidism } & Correlation coefficient & -0.115 & 1.000 & 0.175 \\
\hline & & Sig. $(2 \text {-tailed })^{*}$ & 0.481 & . & 0.281 \\
\hline & \multirow[t]{2}{*}{ EDS } & Correlation coefficient & -0.120 & 0.175 & 1.000 \\
\hline & & Sig. $(2 \text {-tailed })^{¥}$ & 0.459 & 0.281 & - \\
\hline
\end{tabular}


transposition technique had less volar migration at 12-week follow up and less postoperative adhesions (1).

Another study retrospectively evaluated the diagnosis and treatment of 12 CTS cases that developed due to SOL inside the channel (3). Subjects who had space-occupying osseous lesions such as distal Radius fracture or lunate dislocation were excluded. The study included three males and eight females with a mean age of 51 . The subjects were followed for 18 months after the operation, and the CTS diagnosis was made using clinical evaluation and EMG. In cases which were detected to have swelling and tenderness in the wrist line location, imaging studies such as wrist MRI and computed tomography (CT) were used for diagnostic evaluation. Using the classical open surgery technique, SOL was excised. Pathological evaluation of the excised SOL tissues revealed tuberculous tenosynovitis in three cases, nonspecific tenosynovitis in two cases, and gout in one case. Pathological evaluation of the other cases demonstrated CTS due to tumoral lesions in 5 cases; four of them were calcified, and 1 was originated from the ganglion. In postsurgical follow-up, all patients remitted, and no recurrence or complication was seen. The authors concluded that the presence of SOL should be excluded in cases detected to have swelling or tenderness at wrist line location, and imaging studies such as MRI or CT are required for these patients (3).

Our study results demonstrated that there were no tumoral lesions, neural compression due to bone fractures, or ganglion cyst in our study group.

Tanaka et al. (23) investigated whether high-resolution MRI could detect the triangular fibrocartilage complex injuries. High-resolution MRI was performed to subjects who had a positive ulnocarpal stress test and ulnar distal end tenderness at the wrist, and radial attachment, disc, ulnar part of triangular fibrocartilage, ulnotriquetral ligament, palmar radioulnar ligament (PRUL), and dorsal radioulnar ligament (DRUL) were evaluated. They concluded that although high-resolution MRI couldn't exactly detect DRUL, PRUL, and ulnolunate ligament, it was a safe imaging method for the radial part and disc area injuries (23).

Gray et al. (4); performed a prospective cadaver study in horses to evaluate whether CT arthrography was a useful imaging method to examine intercarpal ligament in horses. They found that CT arthrography was a useful imaging method to evaluate intercarpal ligament, and it can be used diagnostically to assess disability due carpal tunnel injury in horses (4).
We used only a wrist MRI to evaluate cases in our study.

A study that emphasized palmar metacarpal region is very important in horses and monkeys because it includes tendons and ligaments which contribute to the grasping of substances evaluated ligaments and tendons belonging to the palmar surface metacarpals of the healthy miniature monkeys $(n=6)$ using MRI (5).

In this study, ligaments and tendons were evaluated by anatomic dissection and MRI, and the authors concluded that MRI was a very useful imaging method to evaluate soft tissues such as tendons and ligaments in the metacarpal region of living mammalian subjects. They detected that the suspensory ligament, deep digital ligament, and inferior check ligament were similar to horse ligaments. They also found that superficial digital flexor ligament has a superficial check ligament that emerges before the carpal joint in these animals. On the other hand, they found that miniature monkeys had another ligament originating from the large metacarpal bone called the second accessory ligament. The authors reported that this ligament could be detected by MRI, a monkey can grasp things thanks to this ligament, and this is a morphological feature for such monkeys (5).

Ikeda et al. (6) used 3-tesla MRI to evaluate the correlation between morphological abnormalities in idiopathic CTS and CTS severity. They evaluated the relationship between CTS severity and cross-sectional areas at multiple levels and performed nerve conduction studies and wrist MRI at both hands of unilateral CTS cases $(n=35)$. At both the affected and unaffected hands median nerve was evaluated at 4 levels: distal radioulnar joint, the corpus of the scaphoid bone, scaphoid tubercle, and hamulus of the hamate bone. TCL thickness was evaluated at 3 regions with MRI and correlated with subjects who were detected to have severe CTS after distal motor latency study. The authors detected that in the affected hand, the median nerve cross-sectional area (MNCA) at the corpus of scaphoid bone was significantly larger than the unaffected hand. In addition, they suggested that the (MNCA) at hand was positively correlated with distal motor latency (6).

In this study, we also excluded Mild CTS patients who have slowed median distal sensory conduction and lower than normal sensory action potential amplitude by orthodromic, antidromic, or palmar pathway, moderate CTS patients who had increased median nerve distal motor latency in addition to mild CTS symptoms, and subjects who had Raynaud phenomenon, and dry skin, swelling, color changes or other autonomic sympathetic 
nervous system involvement findings. The mean age of the cases included in our study was $55.60 \pm 11.38$ years and involved 38 females and 2 males.

\section{CONCLUSION}

In conclusion, contrary to the literature, we couldn't detect a statistically significant association between carpal tunnel area and TCL thickness in this study ( $r s=-0.020 ; p=0.903 ; p>0.05)$. Also, no statistically significant association could be detected between TCL thickness and carpal tunnel area with DM, hypothyroidism, and electrophysiological variables. The low number of cases with endocrinopathies and the inclusion of people from the same race are the limitations of this study.

This prospective study is one of the few studies that compared the carpal tunnel area and TCL thickness using radiological evaluations in CTS patients with or without endocrinopathies. Prospective, multi-center studies that involve CTS patients with endocrinopathies from multiple races are urgently required.

\section{Ethics}

Ethics Committee Approval: Namık Kemal Üniversitesi Tıp Fakültesi (date: 25-05-2017; number: 2017/55/05/04).

Informed Consent: Not applicable.

Peer-review: Externally peer-reviewed.

\section{Authorship Contributions}

Surgical and Medical Practices: N.K., A.T.Ş., Concept: N.K., A.T.Ş., K.Ö., Design: N.K., A.T.S., K.Ö., Data Collection or Processing: N.K., A.T.Ş., Analysis or Interpretation: N.K., A.T.S., Literature Search: N.K., A.T.S., A.M.B., Writing: N.K., A.T.S., K.Ö., A.M.B.

Conflict of Interest: No conflict of interest was declared by the authors.

Financial Disclosure: The authors declared that this study received no financial support.

\section{REFERENCES}

1. Netscher D, Mosharrafa A, Lee M, Polsen C, Choi H, Steadman AK, et al. Transversecarpalligament: its effect on flexor tendon excursion, morphologic changes of thecarpal canal, and on pinch and grip strengths after open carpal tunnel release. Plast Reconstr Surg 1997;100:636-42.

2. Schoth F, Kraemer N, Niendorf T, Hohl C, Gunther RW, Krombach GA. Comparison of image quality in magnetic resonance imaging of the knee at 1.5 and 3.0 Tesla using 32-channel receiver coils. Eur Radiol 2008;18:2258-64.

3. Kang HJ, Jung SH, Yoon HK, Hahn SB, Kim SJ. Carpal tunnel syndrome caused by space occupying lesions. Yonsei Med J 2009;50:257-61.
4. Gray SN, Puchalski SM, Galuppo LD. Computed tomographic arthrography of the intercarpal ligaments of the equine carpus. Vet Radiol Ultrasound 2013;54:245-52.

5. Nazem MN, Sajjadian SM. Anatomicaltransversemagnetic resonance imaging study of ligaments in palmar surface of metacarpus in Miniature donkey: identification of a new ligament. Folia Morphol (Warsz) 2017;76:110-6.

6. Ikeda M, Okada M, Toyama M, Uemura T, Takamatsu K, Nakamura H. Comparison of Median Nerve Cross-sectional Area on 3-T MRI in Patients With Carpal Tunnel Syndrome. Orthopedics 2017;40:e77-e81.

7. Yaşar Şirin D, Yılmaz I, İsyar M, Öznam K, Mahiroğulları M. Does leukocyte-poor or leukocyte-rich platelet-rich plasma applied with biopolymers have superiority to conventional platelet-rich plasma applications on chondrocyte proliferation? Eklem Hastalik Cerrahisi 2017;28:142-51.

8. Komur B, Akyuva Y, Karaslan N, Isyar M, Gumustas SA, Yilmaz I, et al Can a Biodegradable Implanted Bilayered Drug Delivery System Loaded with BMP-2/BMP-12 Take an Effective Role in the Biological Repair Process of Bone-Tendon Injuries? A Preliminary Report. J Pharm (Cairo) 2017;2017:7457865.

9. Oznam K, Sirin DY, Yilmaz I, Kaya YE, Isyar M, Gumustas SA, et al. lopromide- and gadopentetic acid-derived preparates used in MR arthrography may be harmful to chondrocytes. J Orthop Surg Res 2017;12:98

10. Gumustas F, Yilmaz I, Yulaf Y, Gokce S, Sabuncuoglu O. Empathy and Facial Expression Recognition in Children With and Without AttentionDeficit/Hyperactivity Disorder: EffeKTS of Stimulant Medication on Empathic Skills in Children with Attention-Deficit/Hyperactivity Disorder. J Child Adolesc Psychopharmacol 2017;27:433-9.

11. Gumustas F, Yilmaz I, Sirin DY, Gumustas SA, Batmaz AG, Isyar M, et al. Chondrocyte proliferation, viability and differentiation is declined following administration of methylphenidate utilized for the treatment of attention-deficit/hyperactivity disorder. Hum Exp Toxicol 2017;36:981-92.

12. Bisson MA, Beckett KS, McGrouther DA, Grobbelaar AO, Mudera V. Transforming growth factor-beta1 stimulation enhances Dupuytren's fibroblast contraction in response to uniaxial mechanical load within a 3-dimensional collagen gel. J Hand Surg Am 2009;34:1102-10.

13. Frieboes LR, Palispis WA, Gupta R. Nerve compression activates selective nociceptive pathways and upregulates peripheral sodium channel expression in Schwann cells. J Orthop Res 2010;28:753-61.

14. Gokce A, Yilmaz I, Bircan R, Tonbul M, Gokay NS, Gokce C. Synergistic Effect of TGF- $\beta 1$ And BMP-7 on Chondrogenesis and Extracellular Matrix Synthesis: An In Vitro Study. Open Orthop J 2012;6:406-13.

15. 15.Gökçe A, Yılmaz I, Gökay NS, Can L, Gökçe C. Does insulin, transferrin and selenous acid preparation effect chondrocyte proliferation? Acta Orthop Traumatol Turc 2014;48:313-9.

16. Yilmaz I, Gokay NS, Gokce A, Tonbul M, Gokce C. A Novel designed chitosan based hydrogel which is capable of consecutively controlled release of TGF-Beta 1 and BMP-7. Turkiye Klinikleri J Med Sci 2013;33:1832.

17. Yilmaz I, Gokay NS, Bircan R, Saracoglu GV, Dervisoglu S, Gokce A. How different methodologies of harvesting and analysing the samples affect the test results in determining joint mediators. Arthritis 2013;2013:631959.

18. Isyar M, Yilmaz I, Sirin DY, Yalcin S, Guler O, Mahirogullari M. A practical way to prepare primer human chondrocyte culture. J Orthop 2016;13:162-7. 
19. Isyar M, Bilir B, Yilmaz I, Cakmak S, Sirin DY, Guzelant AY, et al. Are biological agents toxic to human chondrocytes and osteocytes? J Orthop Surg Res 2015;10:118.

20. Li Pi Shan R, Nicolle M, Chan M, White C, Winston P, et al. Electrodiagnostic Testing and Treatment for Carpal Tunnel Syndrome in Canada. Can J Neurol Sci 2016;43:178-82.

21. Chen P, Maklad N, Redwine M, Zelitt D. Dynamic high-resolution sonography of the carpal tunnel. AJR Am J Roentgenol 1997;168:533-7.

22. Szabo RM, Madison M. Carpal tunnel syndrome. Orthop Clin North Am 1992;23:103-9.

23. Tanaka T, Yoshioka H, Ueno T, Shindo M, Ochiai N. Comparison between high-resolution MRI with a microscopy coil and arthroscopy in triangular fibrocartilage complex injury. J Hand Surg Am 2006;31:1308-14.

24. Hayes EP, Carney K, Wolf J, Smith JM, Akelman E. Carpal Tunnel Syndrome. In: Mackin EJ, Callahan AD, Skirven TM, Schneider LH, Osterman AL: Rehabilitation of the Hand and Upper Extremity. 5th edition. St. Louis, CV Mosby; 2002, 643-59.
25. Fornage BD, Schernberg FL, Rifkin MD. Ultrasound examination of the hand. Radiology 1985;155:785-8.

26. Finsen VV, Russwurm H. Neurophysiology not required before surgery for typical carpal tunnel syndrome J Hand Surg [Br] 2001;26:61-4.

27. Kantarci F, Ustabasioglu FE, Delil S, Olgun DC, Korkmazer B, Dikici AS, et al. Median nerve stiffness measurement by shear wave elastography: a potential sonographic method in the diagnosis of carpal tunnel syndrome. Eur Radiol 2014;24:434-40.

28. Visser LH, Ngo Q, Groeneweg SJ, Brekelmans G. Long term effect of local corticosteroid injection for carpal tunnel syndrome: a relation with electrodiagnostic severity. Clin Neurophysiol 2012;123:838-41.

29. Schmid, Annina B. Strudwick MW, Little M, Coppieters MW. Effect of splinting and exercise on intraneural edema of the median nerve in carpal tunnel syndrome-an MRI study to reveal therapeutic mechanisms. J Orthop Res 2012;30:1343-50.

30. de Krom MC, Kester AD, Knipschild PG, Spaans F. Risk factors for carpal tunnel syndrome. Am J Epidemiol 1990;132:1102-10. 